\title{
THE GENETIC PROPERTIES OF EGG LAYING OF VIRGIN FEMALES OF TRIBOLIUM CASTANEUM
}

\author{
C. LÓPEZ-FANJUL* and B. JÓDAR \\ Departamento de Genética, Instituto Nacional de Investigaciones Agrarias, \\ Avda. de Puerta de Hierro s/n, Madrid-3, Spain
}

Received 29.xi.76

\begin{abstract}
SUMMARY
Inbreeding was established by brother-sister matings and it was carried out for seven generations in the Consejo population of Tribolium castaneum. From 105 inbred lines at the start, 53 lines reached the end of the experiment. Losses of lines were independent of the level of inbreeding.

The trait studied was 4-day egg laying of virgin females. It has been shown that this trait did not present either inbreeding depression or hybrid vigour. The phenotypic variance and its between- and within-line components also behaved as expected under the additive model as inbreeding progressed. Estimation of genetic parameters in the base population confirmed that egg laying of virgin females is an essentially additive trait.

Other traits-2-day egg laying of fecundated females, precocity and percentage viability - showed a smaller heritability than egg laying of virgin females and considerable inbreeding depression. No connection was found between virgin female egg laying and percentage viability.

The suggestion is made that egg laying of virgin females in the Consejo population can be considered a peripheral trait with respect to fitness.
\end{abstract}

\section{INTRODUCTION}

Populations are constantly subjected to the action of natural selection tending to increase fitness. Fisher's (1930) fundamental theorem of natural selection states that the rate of increase of the reproductive fitness of a population at any given moment is directly proportional to the additive genetic variance of fitness of the population at that moment. Therefore, a population at genetic equilibrium should have very little or no additive variance for fitness. The genetic properties of a quantitative trait in a population, as we see them at present, must be the product of the action of natural selection in the past through a functional relationship between the trait and fitness itself (Robertson, 1955). The secondary theorem of natural selection states that the rate of change of the mean of a metrical character is proportional to the additive genetic covariance between the character and fitness (Robertson, 1968).

Experimentally, the problem of determining the genetic properties of a quantitative trait can be approached either by chromosome assay, a technique practically restricted to Drosophila (Kearsey and Kojima, 1967), or by statistical analysis of the genotypic variation. In the latter case, the ratio between the additive and the total genetic variances can be used as an indication of the closeness of the relationship between the trait and fitness.

* Permanent address: Departamento de Genética, Facultad de Biología, Universidad Complutense de Madrid, Ciudad Universitaria, Madrid-3. 
This ratio is expected to decrease as the relation becomes closer (Falconer, 1960). Unfortunately, the total genetic variance for a given trait is very difficult to estimate in a panmictic population. On the other hand, as inbreeding depression and its converse hybrid vigour are related to a proportion of the non-additive genetic variance, traits showing greater inbreeding depression are expected to be those more closely connected to fitness. Thus, the fundamental and the secondary theorems of natural selection provide the framework within which the relationship between a quantitative trait and fitness can be discussed.

The present experiment follows the approach outlined above in the study of the genetic architecture of egg laying of virgin females in a long-established laboratory population of Tribolium castaneum, a trait which might be considered at first sight as one related to fitness. Results from a preliminary experiment have been already reported by Zornoza and López-Fanjul (1975).

\section{Material AND Methods}

The Consejo population is a pool of several wild populations captured near Madrid and has been maintained in cages in this laboratory at $33^{\circ} \mathrm{C}$ (Orozco and Bell, 1974a).

The traits considered were: (1) 4-day egg laying of virgin females scored from the 7 th to the 11 th day after adult emergence; (2) 2-day egg laying of fecundated females scored from the 11 th to the 13th day after adult emergence; (3) precocity, measured individually as the offspring number of larvac, pupae and adults scored after 21 days from mating; (4) percentage viability, measured individually as the ratio of the number of adult offspring present after 40 days from mating to the number of eggs laid by the fecundated female during the 2-day period mentioned above.

All lines in this experiment were kept at 70 per cent relative humidity and $33^{\circ} \mathrm{C}$, except for egg laying tests which were carried out either at $33^{\circ} \mathrm{C}$ or $28^{\circ} \mathrm{C}$. The culture medium consisted of 95 per cent whole wheat flour and 5 per cent dried brewer's yeast.

From a large sample of pupae of each sex from the population cage, two random samples (I and II) of 110 males and 110 females each were taken and individually mated at random in vials within each sample. From sample I, 105 inbred lines were established by brother-sister single pair matings and continued for eight generations. These lines were maintained by a single pair chosen at random every generation; only if this pair reproduced did the line survive, no substitutions having been made. From sample II, a control line was established and it was reproduced each generation by 100 single pair random matings, each contributing one offspring of either sex to the next generation. When sterile matings occurred, additional matings were made in the next generation in an atternpt to maintain the number of families in the control line at 100. As all females had been scored for virgin egg laying prior to mating, when a line or family were lost infertility necessarily arose after this period. It has not been possible from our data to ascribe the loss of a line (family) to male or female infertility separately.

Egg laying tests were made every generation at $33^{\circ} \mathrm{C}$ and $28^{\circ} \mathrm{C}$ on samples of about 16 virgin females each per inbred line and of about five virgin females from each family of the control line, respectively. At generation 7 
of inbreeding, precocity and percentage viability were measured in both the surviving inbred lines and the control line. Both inbred and control lines were contemporaries during the whole experiment.

\section{Results}

\section{(i) The base population}

The parameters of the base population for the four characters studied are given in table 1 , together with other heritability estimates for egg laying of virgin females at the two temperatures considered, already reported for the Consejo population. Both mean and variances of virgin female egg laying were higher at $33^{\circ} \mathrm{C}$.

\section{TABLE 1}

Parameters of the base population for egg laying of virgin females at $33^{\circ} \mathrm{C}$ (LV33) and $28^{\circ} \mathrm{C}(\mathrm{LV} 28)$, egg laying of fecundated females at $33^{\circ} \mathrm{C}(\mathrm{LF})$ and percentage viability at $33^{\circ} \mathrm{C}(\% \mathrm{~V})$

$\begin{array}{lcccr} & \text { LV33 } & L V 28 & L F & \% V \\ \text { Mean } & 22 \cdot 31 & 15 \cdot 11 & 28.65 & 75 \cdot 19 \\ \text { Standard deviation } & 0.27 & 0 \cdot 19 & 0 \cdot 43 & 0 \cdot 87 \\ \text { Phenotypic variance } & 209.73 & 101.66 & 82 \cdot 02 & 295.93 \\ \text { Coefficient of variation (\%) } & 65 & 67 & 32 & 23 \\ & & & & \\ \text { Variance components: } & & & & \\ \text { Within-family } & 169.06 & 80.20 & 70 \cdot 19 & 269.57 \\ \text { Between-family } & 32.21 & 16.08 & 11.83 & 26.36\end{array}$

Heritability \pm S.E. :

Full-sister correlation

Daughter-dam regression
(a) $0.31 \pm 0.04$
(b) $0.38 \pm 0.04$
$0 \cdot 32 \pm 0 \cdot 04$
$0 \cdot 29 \pm 0.09$
$0 \cdot 17 \pm 0.09$
(c) $0 \cdot 30 \pm 0 \cdot 06$
(d) $0.38 \pm 0.04$
$0 \cdot 33 \pm 0 \cdot 04$
$0.33 \pm 0.04$
(a) $0.30 \pm 0.06$
(b) $0.37 \pm 0.02$
(c) $0.27 \pm 0.02$
(d) $0.36 \pm 0.03$
$0.27 \pm 0.02$
$0.26 \pm 0.03$

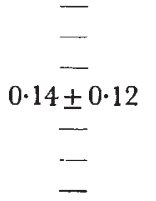
\pm
-
-
-
-
-

(a) Present work; (b) Orozco and Bell (1974a); (c) Ruano, Orozco and López-Fanjul (1975); (d) Orozco (1976b).

Heritabilities have been calculated by full-sister correlation and daughterdam regression analyses. Twice the difference between these heritabilities estimates the relative importance of the dominance and maternal effects plus a fraction of the epistatic effects (Dickerson, 1959). For egg laying of virgin females at $33^{\circ} \mathrm{C}$ this difference was 0.02 with an approximate standard error of $0 \cdot 14$. This estimate is in very good agreement with others obtained at $33^{\circ} \mathrm{C}$ (table $\mathrm{l}$ ) indicating the essentially additive nature of this trait in the Consejo population. A regression estimate of the heritability of egg laying of virgin females at $28^{\circ} \mathrm{C}$ could not be obtained from our data. Significant differences between the correlation and the regression estimates of the heritability of this trait have been obtained by Orozco and Bell (1974a) and Orozco $(1976 b)$ who interpreted them as evidence of dominance gene action for this trait. 
Although fecundated females were only allowed a laying period of 2 days, they laid more eggs than virgin females, in agreement with the results obtained by Orozco and Tagarro (1969). Both egg laying of fecundated females and percentage viability show a smaller heritability than egg laying of virgin females. Estimates of the genetic and phenotypic correlations between egg laying at $33^{\circ} \mathrm{C}$ of virgin and fecundated females in the base population were obtained by full-sister analysis of variance and covariance. Those estimates were $0 \cdot 41 \pm 0 \cdot 12$ and $0 \cdot 19 \pm 0 \cdot 09$, respectively.

\section{(ii) The inbreeding results for egg laying of virgin females}

The structure of control and inbred lines is shown in table 2. From 100 pair matings set up every generation in the control line, the average loss amounted to 11 per cent families per generation. Using this figure as an estimate of loss we would expect 52 inbred lines to survive after seven generations of inbreeding, in extremely good agreement with the 53 lines

TABLE 2

Structure of control (C) and inbred (I) lines at different generations

\begin{tabular}{|c|c|c|c|c|}
\hline \multirow[t]{2}{*}{$\begin{array}{l}\text { Generation } \\
\text { of inbreeding }\end{array}$} & \multicolumn{2}{|c|}{$\begin{array}{c}\text { Number of } \\
\text { families (lines) scored }\end{array}$} & \multicolumn{2}{|c|}{$\begin{array}{l}\text { individuals scored } \\
\text { per family (line) }\end{array}$} \\
\hline & $C$ & $I$ & $C$ & $I$ \\
\hline 1 & 99 & 105 & $4 \cdot 69$ & 13.86 \\
\hline 2 & 86 & 99 & $4 \cdot 23$ & $14 \cdot 02$ \\
\hline 3 & 79 & 89 & 4.91 & $20 \cdot 22$ \\
\hline 4 & 91 & 83 & 4.89 & $19 \cdot 22$ \\
\hline 5 & 89 & 73 & $4 \cdot 25$ & $14 \cdot 11$ \\
\hline 6 & 90 & 60 & $4 \cdot 77$ & 13.57 \\
\hline 7 & 91 & 53 & $4 \cdot 84$ & $15 \cdot 66$ \\
\hline
\end{tabular}

which actually reached the end of the experiment. Losses of inbred lines appear then to be independent of the inbreeding process. Moreover, no significant differences were found between the frequency distributions of egg laying at both temperatures for all inbred lines and for those surviving after seven generations of inbreeding ( $P>70$ per cent). Similarly, the differences between the distributions of the means for all inbred lines and for those surviving were also non-significant at any temperature $(\mathrm{P}>80 \mathrm{pcr}$ cent).

The means, phenotypic variances and variance components of both control and inbred lines are shown in table 3. Inbred lines considered as a whole and those surviving both behave in a similar manner. In consequence, only data corresponding to the latter lines are shown. Strong fluctuations of these parameters occurred throughout the experiment unassociated with any known culture change. Higher means tended to correspond to higher variances probably due to the positive correlation existing between the mean and the variance for the traits studied. The data were left untransformed as no appropriatc scale transformation has been found rendering the mean and the variance uncorrelated (Orozco, 1976a). The differences between the means of control and inbred lines at the two temperatures showed no specific tendency during the entire experiment, indicating the absence of 
inbreeding depression. At $33^{\circ} \mathrm{C}$, the differences between the control and the inbred lines for the phenotypic and the within-line variance did not follow any specific trend as inbreeding progressed. For egg laying at $28^{\circ} \mathrm{C}$, the values of these parameters were in general lower in the control line. The between-line variance at both temperatures shows a clear-cut increase as inbreeding progresses. This variance was always larger than the variance between families of the control line in all generations.

Inbred lines were random crossed in pairs at generation 6 and $50 F_{1}$ progeny from 22 out of the 26 possible crosses being obtained and scored at $33^{\circ} \mathrm{C}$. In spite of large differences between the means of the reciprocal $F_{1}$

TABLE 3

Means and phenotypic, within-family (line) and between-family (line) variances of control (C) and inbred (I) lines for each level of inbreeding (F)

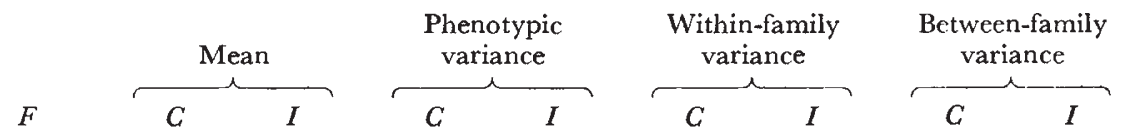

\begin{tabular}{|c|c|c|c|c|c|c|c|c|}
\hline $0 \cdot 250$ & $19 \cdot 4$ & $18 \cdot 9$ & $162 \cdot 8$ & 144.6 & $139 \cdot 6$ & $120 \cdot 9$ & $23 \cdot 2$ & $23 \cdot 7$ \\
\hline 0.375 & $19 \cdot 7$ & $22 \cdot 3$ & $151 \cdot 6$ & $222 \cdot 4$ & $133 \cdot 2$ & $175 \cdot 6$ & $18 \cdot 4$ & $46 \cdot 8$ \\
\hline 0.500 & $27 \cdot 2$ & $22 \cdot 7$ & 203.5 & $185 \cdot 1$ & $172 \cdot 0$ & $147 \cdot 6$ & $31 \cdot 5$ & $37 \cdot 5$ \\
\hline 0.594 & $22 \cdot 9$ & $23 \cdot 5$ & $189 \cdot 0$ & $246 \cdot 7$ & $170 \cdot 7$ & $183 \cdot 3$ & $18 \cdot 3$ & $63 \cdot 4$ \\
\hline $0 \cdot 672$ & $18 \cdot 9$ & $21 \cdot 7$ & $162 \cdot 8$ & $225 \cdot 9$ & $135 \cdot 1$ & $155 \cdot 6$ & $27 \cdot 7$ & $70 \cdot 3$ \\
\hline 0.734 & $24 \cdot 4$ & $19 \cdot 9$ & $233 \cdot 8$ & 195.5 & $182 \cdot 2$ & 139.5 & $51 \cdot 6$ & $56 \cdot 0$ \\
\hline 0.785 & $23 \cdot 6$ & $20 \cdot 1$ & $294 \cdot 6$ & $227 \cdot 5$ & $239 \cdot 5$ & $158 \cdot 2$ & $55 \cdot 1$ & $69 \cdot 3$ \\
\hline
\end{tabular}

(b) Egg laying of virgin females at $28^{\circ} \mathrm{C}$

$\begin{array}{lrrrrrrrr}0 \cdot 250 & 11 \cdot 0 & 12 \cdot 4 & 78 \cdot 7 & 83 \cdot 7 & 70 \cdot 1 & 72 \cdot 2 & 8 \cdot 6 & 11 \cdot 5 \\ 0 \cdot 375 & 14 \cdot 3 & 17 \cdot 4 & 89 \cdot 6 & 133 \cdot 2 & 76 \cdot 8 & 106 \cdot 5 & 12 \cdot 8 & 26 \cdot 7 \\ 0 \cdot 500 & 18 \cdot 7 & 17 \cdot 3 & 111 \cdot 5 & 127 \cdot 0 & 94 \cdot 2 & 97 \cdot 2 & 17 \cdot 3 & 29 \cdot 8 \\ 0 \cdot 594 & 15 \cdot 8 & 16 \cdot 8 & 81 \cdot 1 & 116 \cdot 8 & 69 \cdot 0 & 87 \cdot 9 & 12 \cdot 1 & 28 \cdot 9 \\ 0 \cdot 672 & 15 \cdot 4 & 14 \cdot 0 & 111 \cdot 8 & 104 \cdot 3 & 95 \cdot 6 & 80 \cdot 6 & 16 \cdot 2 & 23 \cdot 7 \\ 0 \cdot 734 & 16 \cdot 5 & 16 \cdot 0 & 100 \cdot 9 & 135 \cdot 4 & 73 \cdot 4 & 87 \cdot 8 & 27 \cdot 5 & 47 \cdot 6 \\ 0 \cdot 785 & 14 \cdot 5 & 16 \cdot 3 & 104 \cdot 2 & 118 \cdot 2 & 86 \cdot 5 & 80 \cdot 3 & 17 \cdot 7 & 37 \cdot 9\end{array}$

crosses, the differences between the $F_{1}$ means and the corresponding midparental values were only found to be significant at the 5 per cent level in two cases. The regression coefficient of crossbred $\left(F_{1}\right)$ mean on mid-parental mean was estimated to be $1 \cdot 03 \pm 0 \cdot 27$.

\section{(iii) The effect of inbreeding on other traits}

The performance of the control and the inbred lines for egg laying of fecundated females, precocity and egg to adult viability was examined at the end of the experiment. These three characters presented considerable inbreeding depression (table 4), indicating the presence of non-additive genetic effects. This result also shows that the inbreeding process carried with it an increase in the level of homozigosity in spite of the absence of inbreeding depression for egg laying of virgin females.

The relationship between egg laying of virgin females and other traitsegg laying of fecundated females and percentage viability-was also investi- 
gated both in the control and the inbred lines at generation 7 and the results are presented in table 5. A significant positive association was found between virgin and fecundated female egg laying, although the measure of the association indicates only a small degree of dependence (genetic correlation $0 \cdot 41$ ). On the other hand, the trait more closely connected to fitness of all traits studied-percentage viability - was found to be unassociated with egg laying of virgin females at $33^{\circ} \mathrm{C}$ ( $\mathrm{P}<5$ per cent). In no case was an indication found of the existence of a favoured intermediate phenotype for egg laying. Unfortunately, the connection between egg laying of virgin females and precocity could not be investigated with our data.

Table 4

Means ( \pm S.E.) of control (C) and inbred lines (I) at generation 7 of inbreeding for egg laying of fecundated females (LF), percentage viability (\% V) and precocity (P) (a)

$\begin{array}{cccccc}\text { Line } & L F & \% V & \overbrace{\text { \% larvae }} \% \text { pupae } & \% \text { adults } \\ C & 28 \cdot 65 \pm 0.43 & 75 \cdot 19 \pm 0.87 & 10 & 88 & 2 \\ I & 21.37 \pm 0.37 & 44.42 \pm 0.83 & 45 & 55 & 0\end{array}$

(a) Based on about 400 and 700 individuals scorcd for the $C$ and $I$ lines, respectively for all traits.

TABLE 5

Egg laying of fecundated females (LF) and percentage viability $(\% \mathrm{~V})$ for the different classes of egg laying of virgin females at $33^{\circ} \mathrm{C}(\mathrm{LV} 33)$, for the control (C) and the surviving inbred (I) lines (a)

\begin{tabular}{|c|c|c|c|c|c|c|c|}
\hline & \multicolumn{7}{|c|}{ Class interval (LV33) } \\
\hline & $0-9$ & $10-19$ & $20-29$ & $30-39$ & $40-49$ & $50-59$ & $>60$ \\
\hline$C$ & $24 \cdot 67$ & $26 \cdot 95$ & $29 \cdot 39$ & $30 \cdot 54$ & $31 \cdot 67$ & $36 \cdot 06$ & $38 \cdot 45$ \\
\hline & $17 \cdot 58$ & $20 \cdot 47$ & $23 \cdot 99$ & $26 \cdot 01$ & $28 \cdot 51$ & $27 \cdot 94$ & $31 \cdot 94$ \\
\hline$V\left\{\begin{array}{l}C \\
J\end{array}\right.$ & $76 \cdot 36$ & 74.53 & 74.06 & $76 \cdot 45$ & $74 \cdot 46$ & 73.34 & $74 \cdot 70$ \\
\hline & $43 \cdot 30$ & $45 \cdot 08$ & $45 \cdot 92$ & $46 \cdot 02$ & $40 \cdot 39$ & $42 \cdot 45$ & $36 \cdot 82$ \\
\hline
\end{tabular}

(a) Based on about 400 and 700 individuals scored for the $C$ and $I$ lines, respectively for all traits.

\section{Discussion}

In a model of complete additive gene action, a trait subjected to inbreeding must not show either inbreeding depression or hybrid vigour. Besides, the changes in the total genetic (additive) variance and variance components for a set of lines all inbred by an amount $F$ can be predicted in terms of their original values in the base population under panmixia $(F=0)$ and their inbreeding coefficient. The within-line genotypic variance decreases by a factor of $(1-F)$, the between-line genotypic variance changes by a factor of $2 F$ and the total genotypic variance increases by a factor of $(1+F)$. This prediction is strictly true only when inbreeding is slow but with rapid inbreeding similar results can be expected except in the first few generations (Wright, 1951). In our case, the character egg laying of virgin females can be said to fulfil essentially all these conditions. Of course, for a trait 
with a heritability of 0.30 and a coefficient of variation of about 65 per cent, the expected changes in the total genotypic and within-family genotypic variance would mostly go undetected as they have to be inferred from their corresponding phenotypic values which will, in turn, fluctuate widely. On the other hand, changes in the between-line variance will be easier to detect as this parameter is free of environmental effects. This has actually happened in our experiment.

For the above predictions to be valid two more assumptions have to be met. In the first place, the environmental variance should not change with inbreeding. This appears to be the case as the difference between the phenotypic variances in the control and the inbred lines does not follow any specific trend throughout the experiment. Secondly, there should be no selection for the trait considered at any stage. This also seems to be the situation as no differences were detected between the distributions of the trait in inbred lines as a whole and in those surviving. We can therefore conclude that egg laying of virgin females at $33^{\circ} \mathrm{C}$ and $28^{\circ} \mathrm{C}$ is essentially an additive trait within the power of resolution of our techniques. This conclusion does not preclude the existence of loci showing non-additive gene action for the trait but the gene frequencies of these loci in the base population should be low enough not to be detected by inbreeding, although these frequencies may be increased by recurrent selection (Orozco and Bell, 1974b).

Under the circumstances described, natural selection should have acted on the trait in the way described by Fisher's theorem provided a relationship between the trait and fitness exists. This is in contradiction with the presence of a large additive component of the genetic variance for egg laying of virgin females. Alternatively, centripetal selection could result in an essentially additive trait (Mather, 1953). Although our evidence is limited to one major component of fitness-percentage viability-no relation could be detected between this trait and egg laying, either in the control or in the inbred lines, in spite of the strong modifications of the gene frequency array which should be carried out by the inbreeding process.

However, it is quite possible that the selection pressure on the trait may be small and consequently its effect will not be detectable, making it impossible to differentiate a strictly neutral trait with respect to fitness from a peripheral trait, which lies outside the path linking primary gene action to reproductive fitness (Robertson, 1955). Judging from our data, egg laying of virgin females can then be considered a peripheral trait with respect to fitness in the Consejo base population. On the other hand, Orozco (1972) has shown that the peripheral nature of this trait disappears when the frequency array of the genes controlling virgin egg laying is modified by long-term artificial selection, which alters the position of the trait in relation to fitness.

Acknowledgment.--We wish to thank Dr M. C. Fuentes for her technical assistance.

\section{REFERENGES}

Dickerson, G. E. 1959. Techniques for research in quantitative animal genetics. Techniques and Procedures in Animal Production Research, edited by the American Society of Animal Production, pp. 57-105.

FALCONER, D. s. 1960. Introduction to Quantitative Genetics, pp. 330-337, Oliver and Boyd, Edinburgh.

$39 / 2-\mathrm{E}$ 
FISHer, R. A. 1930. The Genetical Theory of Natural Selection. 2nd edition, pp. 37-51. Dover Publications, New York.

KEARSEY, M. J. AND KOJIMA, K. 1967. The genetic architecture of body weight and egg hatchability in Drosophila melanogaster. Genetics, 56, 23-37.

MATHER, к. 1953. The genetical structure of populations. Symposium of the Sociely for Experimenial Biology, 7, 66-95.

orozco, F. 1972. Influence of fitness deterioration on selection limits. Annales de Génétique et de Sélection animale, 4, 569-592.

orozco, F. 1976a. Changes of scale in the study of the evolution of the genetic variance through selection in Tribolium castaneum. Annales de Génétique et de Sélection animale, 7, 205-223.

OROzco, F, 1976b. A dynamic study of genotype-environment interaction with egg laying of Tribolium castaneum. Heredity, 37, 157-171.

ORozco, F. AND BELL, А. E. 1974a. A genetic study of egg laying of Tribolium castaneum in optimal and stress environments. Canadian Fournal of Genetics and Citology, 16, 49-60.

OROZCO, F. AND BELL, A. \&. 1974b. Reciprocal recurrent selection compared to withinstrain selection for increasing rate of egg lay of Tribolium under optimal and stress conditions. Genetics, 77, 143-161.

OROzCo, F. AND TAGARRo, M. P. 1969. Respuesta a la selección y parámetros de la puesta de huevos en una estirpe de Tribolium castaneum. Boletin del Institulo Nacional de Investigaciones Agronómicas, 29, 203-220.

ROBERTSON, A. 1955. Selection in animals: Synthesis. Cold Spring Harbor Symposium on Quantitative Biology, 20, 225-229.

robertson, A. 1968. The spectrum of genetic variation. Population Biology and Evolution, ed. by R. C. Lewontin, pp. 5-16. Syracuse University Press, Syracuse, N.Y. (U.S.A.). RUANo, R. G., OROzco, F. AND López-FAnjul, C. 1975. The effect of different selection intensities on selection response in egg-laying of Tribolium castaneum. Genetical Research, $25,17-27$.

WRIGHT, s. 1951. The genetical structure of populations. Annals of Eugenics, 15, 323-354. zORNOZA, P. AND LÓPEZ-FANJuL, c. 1975. The effect of inbreeding on egg laying of $\mathrm{T}$. castaneum. Tribolium Information Bulletin, 18, 152-155. 